\title{
The Construct, Measurement, and Impact of Employee Engagement: a Marketing Perspective
}

\author{
V. Kumar • Anita Pansari
}

Published online: 15 January 2014

(C) Springer Science+Business Media New York 2014

\begin{abstract}
In this study, we establish how marketing can play a significant role in extracting value from the crucial management construct - employee engagement (EE). To do so, first, we discuss the construct of EE through a detailed review of the relevant literature and the insights gleaned from our interviews with managers from across five continents. Second, we provide a formal definition for EE, develop scales for measuring $\mathrm{EE}$, and then argue how enhancing EE can improve firm performance. After refining the measurement scales, we collect data from two countries and analyze the process of EE by conducting a path analysis and validating the findings from the popular press articles. This research provides guidance to managers on measuring and managing the different factors that drive employee engagement, thereby generating a blueprint for enhancing the firm's service delivery, customer satisfaction, and resultant firm performance.
\end{abstract}

Keywords Employee engagement · Firm performance . Services $\cdot$ Scales

\section{Introduction}

The intensity of competition, technological advances, and globalization have together contributed in making markets both very complex and highly competitive. Customers' expectations for product customization and heterogeneity in customers' demands have pressured firms to develop

\section{Kumar $(\bowtie) \cdot$ A. Pansari}

Centre for Excellence in Brand and Customer Management at the

J. Mack Robinson College of Business, Georgia State University,

Atlanta, GA, USA

e-mail: vk@gsu.edu

A. Pansari

e-mail: Apansari1@gsu.edu strategies focusing on customer interactions which are essential for survival [1]. In such a competitive market structure, firms always want to carve a niche for themselves and stand out from the competition, either in the form of exceptional service or superior products or both. Towards this end, we introduce the concept of employee engagement (EE) in this study and show that it is relevant and can contribute to differentiation in both service-based and manufacturing companies. Our study also discusses how EE is more readily visible in service-based companies where employees are the face of the organization, interacting with customers at every touch point. Employees directly influence customer perceptions about the brand, and these perceptions can be enhanced if the employees engage effectively with the customers. We also show that although EE is not directly visible in manufacturing companies, its impact can be seen in the quality of the products, reduced training costs, reduced labor outrages, and increased profits.

In a market where most products are homogenous in nature, exceptional service could be an inimitable competitive advantage for firms. Service is more of a competency than an asset, which is also why exceptional service is difficult to replicate in entirety, as opposed to an exceptional product, which can be replicated with relative ease. Competing through service is possible only when the whole organization is service dominant and the organization treats its employees as a valuable resource [2]. In other words, if a firm wants to be able to deliver exceptional, inimitable service, it must focus on hiring, training, and retaining the right kind of employees. Consider these statistics:

- US organizations spent approximately US\$156.2 billion on employee learning in 2011 [3].

- Average direct expenditure per employee in 2011 was US\$1,182. ${ }^{1}$

\footnotetext{
${ }^{1}$ ibid
} 
- A study by IBM notes that training, which produced an average productivity improvement of only $3 \mathrm{~min} /$ day, would save a company with 1,000 employees at least US\$240,000/year [4].

These statistics bear testimony to the fact that companies realize that employees are an asset and, as a result, choose to invest a huge amount of resources in them. This investment is essential because employees interact with customers on a dayto-day basis and these interactions, if managed efficiently, could be a source of competitive advantage [5]. The employees of the organization are primarily responsible for the success of these customer interactions as they are the face of the firm and a key influencer in these interactions. It is the behaviors, attitude, and actions of the employees that can either strengthen a brand's advertised standards or, if inconsistent with these standards, can challenge the credibility of the organization. Moreover, such inconsistencies often get amplified and publicized at the speed of thought in today's social media age. For instance, as a company that professes "We live to deliver" as a motto [6], FedEx and its employees are expected to demonstrate that commitment towards ensuring mail and packages reach their intended recipients in their original form and condition. However, not all FedEx employees seem to have imbibed this commitment. This was proven through some widely circulated, covertly recorded videos of FedEx employees intentionally mishandling packages at different times. The videos were shared and re-shared via social media and, as a result, could have potentially harmed FedEx's brand image and reputation among a widespread audience. A recent study [7] notes that the quality of tires produced by Firestone had deteriorated and the defects were at their peak just before the employees went out on strike. This indicates that unhappy employees can affect the manufacturing sector as well and employees invest more efforts and exercise due diligence only if they feel that they are being treated well.

In order to avoid such mishaps, it is essential to align employees' values, standards, and behaviors with the brand's desired values and standards [8]. Effective internal communication of a brand with its workforce enhances the intellectual and emotional commitment of its employees towards the brand [9]. This has been identified and understood by firms like Wholefoods, Starbucks, Marriot International, Southwest, etc., who not only keep their customers happy but also their employees. $^{2}$

These companies and many more understand that satisfied employees mean more profits. The chairman of Southwest Airlines says "You put your employees first and if you take care of them, then they will take good care of you, and then

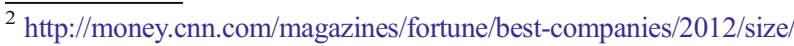

your customers will come back, and your shareholders will like that, so it's really a unity [10]."

Organizations work towards customer satisfaction because it is more profitable to retain existing customers than to attract new customers [11]. Customer satisfaction serves as a particularly important antecedent of customer retention and thus long-term customer relationships [12]. These long-term relationships would be beneficial for the company only if the customer adds revenue to the firm [13]. Customer satisfaction leads to higher profitability only if the satisfied customer buys from the firm regularly [13]. For a customer to buy/consume the products/services of the firm regularly, the services provided by the firm are of key relevance.

In 2012, companies, both commercial and nonprofit, spent approximately US\$168.5 billion on direct marketing, which accounted for $8.7 \%$ of the total gross domestic product of the USA [14]. Companies like Apple Inc. and Verizon have spent US\$333 million [15] and US\$1.64 billion [16], respectively, in 2011-2012, on advertising. This data highlights that companies tend to concentrate their marketing investments only towards consumer awareness and recall, based on the assumption that these investments will prove beneficial by triggering sales and profits. However, in reality, there are several additional factors that can influence profit/sales generation, and companies have to go the extra mile beyond advertising to maximize profits. In reality, the extent of profits that a company generates is directly influenced by the extent of its sales derived from customers' engagement with the company's brand [17].

The key questions that then arise are as follows: Can firms maximize their profits merely on the strength of their financial resources or is there something beyond these resources that can help firms in this endeavor? This paper addresses these questions and adds value to marketing literature by analyzing and documenting the tangible impact of EE in more than one way.

\section{Motivation for Research}

Services, unlike products, are outputs of interactive, cocreation processes. They are produced, delivered, and consumed in a time and space where both the service provider (employees) and the customers are present. Service production primarily involves human resources and, therefore, there are different levels of service quality and productivity in every service organization [18]. "The most vivid service impressions occur during the service encounter or moment of truth, i.e. when customers interact with the service company" [19]. The interactions between customer satisfaction and employee productivity or service quality have a huge impact on the financial performance of firms [20]. There have been various studies that have highlighted the impact of service quality on 
customer satisfaction [20]. There have also been studies which have focused on the customer's impact on firm profitability [21], but there is very limited literature on how employees impact firm profitability and on the tangible impact their engagement levels have on the firm's bottom line. This gap is important to study, as it has been observed that EE predicts employee outcomes, organizational success, and financial performance [22]. Although a relationship has been established between EE and productivity, profitability, employee retention, safety, and customer satisfaction [23] in the literature reviewed, there is no consensus on the definition and the components of the main underlying construct of EE. Therefore, one of the objectives of this study is to define and discuss in detail the construct of EE.

\subsection{Why Is Employee Engagement So Important?}

EE as discussed in the existing literature can foster the development of an organizational ecosystem that delivers superlative solutions to customers. Around $71 \%$ of senior human resource (HR) leaders report employee engagement as a key metric to be included on an HR scorecard for executives. ${ }^{3}$ In a study by Quantum Work Place, it was found that organizations with the highest level of engagement saw the following results:

- Eighty-seven percent showed a predicted increase in revenue in the subsequent 3 years.

- Eighty-six percent reported an increase in market share.

- Fifty-seven percent reported lower employee turnover.

- Ninety percent of the publicly traded clients reported higher stock prices.

A study by Crim and Sejits (2006), defines an "engaged employee" as "a person who is fully involved in, and enthusiastic about, his or her work." This study posits that:

- Eighty-four percent of highly engaged employees believe they can positively impact the quality of their organization's products, compared with only $31 \%$ of the disengaged.

- Seventy-two percent of highly engaged employees believe they can positively affect customer service, versus $27 \%$ of the disengaged.

- Sixty-eight percent of highly engaged employees believe they can positively impact costs in their job or unit, compared with just $19 \%$ of the disengaged.

A Gallup study conducted in 2010 among 47,000 employees over 120 countries indicates that $11 \%$ of workers

\footnotetext{
$\overline{3 \text { http://www.quantumworkplace.com/your-challenges/employee- }}$ engagement/
}

are engaged, $62 \%$ are not engaged, and $27 \%$ are actively disengaged. ${ }^{4}$ They define engagement as the emotional connection an employee has with his/her firm. In this study, the difference in earnings per share (EPS) between companies with low EE and companies with no EE was $19 \%$, while the difference in EPS between companies with high $\mathrm{EE}$ and no EE was a startling $132 \%$. These studies that were conducted in the practitioners' world substantiate the positive impact of EE on a firm's financial performance.

Further, the Gallup survey of 2013 [24] also brings some other alarming statistics to our notice. It indicates that the highest incidence of engaged employees was only $37 \%$ (in Panama) and the global employee disengagement rate was as high as $63 \%$. Employee disengagement invariably causes lost firm productivity and increased costs due to employee absenteeism, turnover, and other factors. Thus, the Gallup survey further emphasizes the importance and the urgency of managing EE effectively in today's market place. Although the survey highlights the disparities in the levels of EE across the globe, it does not analyze the process of EE, the causes behind these disparities, and the factors that influence EE. This gap that exists in both the practitioners' and academicians' world has been studied in depth in our study, which is the first of its kind that builds a construct of EE, designs a framework to measure its incidence and impact, and lays down a roadmap to address shortcomings, if any.

We believe that it is not only essential to understand the factors that contribute towards enhancing EE, but it is also important to study how these factors can be beneficial to organizations in enhancing their profits through superior quality of products and services and reducing their costs through better employee measures. Therefore, this study will focus on EE, its conceptual framework, antecedents, and its contribution to marketing.

\section{Employee Engagement: Literature Review}

\subsection{Concept, Construct, and Definition of Employee Engagement}

The concept of EE was first introduced in the sociopsychological work of Kahn [25], who proposed that personal engagement occurs when "people bring in or leave out their personal selves during work-role performances." There are four major approaches that have been developed to define EE.

The first approach was suggested by Kahn [25] and it is called the need-satisfying approach. In this approach, if the employees are positive about their work being meaningful, their work place being safe and availability of sufficient

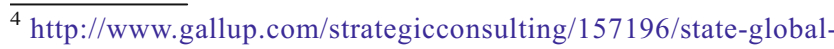
workplace.aspx
} 
resources for completing tasks, then this indicates that the employees are engaged psychologically, socially, and physically when occupying and performing work roles. The next approach to EE was discussed by Maslach et al. [26], where engagement has been operationalized as the reverse of scores on the Maslach Burnout Inventory - it is thought that anyone who is not experiencing a burnout must be engaged. A "burnout" is conceived to be the erosion of engagement. In the third approach, suggested by Harter et al. [27], EE has been defined as an "individual's involvement and satisfaction as well as enthusiasm for work." This approach also concludes that EE has a positive relationship with important business outcomes such as customer satisfaction turnover, safety, productivity, and profitability. The fourth and the final approach of EE is a multidimensional perspective, given by Saks [28]. He theorized EE through a social exchange model and separated job engagement and organizational engagement. He defined EE as "a distinct and unique construct consisting of cognitive, emotional, and behavioral components associated with individual role performance."

Although each approach proposes a different perspective, there is no unanimous and conclusive verdict on the definition of $\mathrm{EE}[28,29]$. Apart from the main approaches discussed above, EE has been defined by various researchers with a few overlapping definitions. Development Dimensions International (DDI) defines it as, "The extent to which people value, enjoy and believe in what they do." DDI also states that the measure of EE is similar to that of employee satisfaction and loyalty; whereas Fleming et al. [30] consider it similar to that of employee commitment, Wellins and Concelman [31] go a step further and combine commitment, loyalty, productivity, pride, etc. in the definition of EE. They define it as "the illusive force that motivates employees to higher levels of performance." This is similar to commitment to the organization, job ownership and pride, more discretionary effort (time and energy), passion and excitement, commitment to execution, and the bottom line. They call it "an amalgam of commitment, loyalty, productivity and ownership." Robinson et al. [32] state that EE is beyond employee commitment, whereas Harter et al. [27] define EE as "the individual's involvement and satisfaction as well as enthusiasm for work." Schaufeli et al. [33] claim that engagement is essential for contemporary organizations given the many challenges they face, whereas Macey et al. [29] state that organizations can gain a competitive advantage through EE. They have demonstrated that among a sample of 65 firms in different industries, the top $25 \%$ on an engagement index had a greater return on assets, a greater profitability, and more than double the shareholder value compared to the bottom $25 \%$. On the other hand, it has also been reported that $\mathrm{EE}$ is on the decline and there is a deepening disengagement among employees today [33].

Due to such contradictory definitions and no consensus on a single definition, many researchers have criticized the construct of EE. They state that it lacks a consistent definition and measurement [34]; therefore, some wonder if the term is really needed and hope it is not just another fad term [35]. The main criticism of the concept of EE stems from the challenge in distinguishing whether EE is a state or behavior [35]. The argument is that the definitions do not clearly note whether EE is an attitude or behavior and if it is a group or an individual phenomenon. Although some consider engagement to be a state [35], others have described it as a psychological state that has behavioral manifestations [36]. It has also been distinguished in terms of feelings, which consist of urgency, focus, intensity, and enthusiasm as well as behaviors, which consist of persistence, proactivity, role expansion, and adaptability [36]. Researchers suggest that, "Perhaps, like organizational culture, EE is a multi-dimensional, multi-layered construct" [37]. It has been recommended that, "The construct should be rigorously tested in order for its theoretical soundness and practical application to be strengthened," because "only by understanding the nature of the construct and its relationship to attitudes, behavioral intentions and behaviors can it be applied to the benefit of organizations and employees" [35].

From the above literature, it can be noted that most researchers agree that EE is desirable, has an organizational purpose, has both psychological and behavioral facets, and involves energy, enthusiasm, and focused effort.

Since there are so many inconsistencies in the literature on the definition of EE and its components, we resorted to the practitioners' perspective to remove the inconsistencies and introduce the concept of EE to marketing academia. We interviewed managers to understand the construct, its meaning, components, and implications. Managerial interviews were sought to understand the current organizational practices and the current understanding on EE. Both the existing theory in the management literature and the managerial interviews helped us define EE as: "A multidimensional construct which comprises of all the different facets of the attitudes and behaviors of employees towards the organization." The dimensions of EE comprise of employee satisfaction, identification, commitment, loyalty, and performance.

EE could often be misinterpreted as "internal marketing." However, these two terms are distinct from one another. The concept of internal marketing was first introduced in 1976 by Parasuraman et al. [38] and has been defined as: "viewing employees as internal customers, viewing jobs as internal products that satisfy the needs and wants of these internal customers while addressing the objectives of the organization." This view, although valid, does not elaborate on the specific impact that employee satisfaction has on customer satisfaction. Offering a different perspective [38], note that: "Internal marketing is a planned effort to overcome organizational resistance to change and to align, motivate and integrate employees towards the effective implementation of corporate and functional strategies." However, this view also focuses on 
satisfaction like [38] and does not explore all the facets of the employee-firm relationship. This is largely because the concept of internal marketing itself is limited to keeping employees happy thereby ensuring they are satisfied with their jobs and work environment.

EE, on the other hand, goes beyond satisfaction and discusses various facets of the employee-firm relationship like employee identification, employee commitment, employee loyalty, and employee performance. Moreover, EE is employee specific and provides solutions for not only achieving higher levels of engagement, but also for more efficient delivery of organizational values and the brand promise to the end customer. Further, internal marketing also encompasses the suppliers and distributors of the firm [90] and EE, as the name suggests, focuses only on the employees of the company.

In service organizations, employees are co-creators of value, sources of innovation, and organizational knowledge. Hence, they are treated as an operant resource [36]. The frontline employees are very important in defining the quality of relationship a customer would have with the service organization [39]. Employee behaviors like customer orientation [40], service orientation [41], organizational citizenship behavior [42], etc. contribute to a positive customer relationship. There is a competitive advantage if the employees who are dedicated to the organization are non-imitable and rare [43]. Employee satisfaction also affects the behavior of the employee towards the brand [44], which, in turn, affects the commitment of employees towards the organization [45]. Employees who are committed to the organization would stay longer in the organization (loyalty) and would perform better [46].

From the above discussion, it is understood that there are various studies on one or more of the above constructs, but there is not a single study which integrates all the constructs in a single, multidimensional framework of EE. Moreover, there is no consensus on the definition of EE across the literature. In order to accurately identify and analyze all the factors that were part of the construct, we conducted qualitative research among managers across the world, to derive practitioners' insights and perspective on the components of EE. The next section discusses this qualitative research in detail.

\subsection{Analysis of the Managerial Interviews}

We conducted our qualitative research across the continents of North America, South America, Asia, Africa, and Europe. We initially contacted 124 companies of which only 52 companies permitted us to interview their managers. A majority of the firms interviewed were service organizations across various industries ranging from hotels, telecom, airlines, to retail and banking. The highest numbers of participating firms were from North America (13 companies), followed by Asia (11 companies), South America, and Europe (10 companies) and the least numbers of participants were from Africa $(8$ companies). We interviewed HR and marketing managers from these companies. In the first round of the interviews, the managers were sent emails to solicit their participation in the study. Emails were sent to at least two managers from each company. After receiving their consent, 194 managers were interviewed over the phone and 14 managers were interviewed in person. There were at least two HR and two marketing managers from each firm that participated in the interviews.

Managers in Asia noted that the key concern for organizations was to retain employees. An HR manager from a leading banking organization in India admitted to the employee attrition rate being very high at his organization, with most of the employees leaving within 2 years of joining. The manager further noted that such attritions were a huge loss for the company, as a lot of money was invested towards employee training and development. Across the board, the marketing managers that were interviewed expressed deep concerns about disengaged employees who quit and eventually end up poaching clients from their former employer: "Our customers are attached to the employee serving them, if the employee moves to the competition; he takes his clients with him." On the other hand, some managers admitted to facing challenges with long tenured employees not being as productive as they used to be in the early years of their tenure with the organization. Others raised concerns on the whole team following their supervisor to his new employer. In a leading bank in India, a senior executive quit and joined a competitor bank and within a month, and his former team followed him to his new employer. From a firm's point of view, such incidents are undesirable and need to be avoided as they would much rather have employees be loyal to the firm than to the individual they report to.

In other continents like North America and Europe, there were different challenges. Here, unlike in Asia, the challenge was not in retaining employees or ensuring their loyalty but rather in ensuring employees were performing at their highest levels of productivity. Companies noted that the employees found it difficult to connect with a varied range of customers and did not treat the company as their own. The key problem managers faced here was the absence of a sense of ownership among employees.

Before interviewing the managers, our notion was that employee loyalty would be high in the emerging markets and low in the developed nations, given their economic stability. However, we were surprised to hear from managers that loyalty was a concern in the emerging markets instead because of the enormous growth opportunities and employment alternatives in these nations, whereas it was not a concern at all in the developed nations. The challenge in the developed nations was the absence of a sense of ownership and commitment.

Many such differences prodded us to further examine the scenario. The managerial interviews were conducted during 
the period of April 2011-October 2012. Based on the managerial interviews and the insights gleaned from the relevant academic literature, we arrived at the components of EE and the logical path for maximization of firm performance. Managers around the world helped us by discussing the importance of each component of employee engagement and the cause and effect of the same. This discussion and the relevant literature led us to our conceptual framework. In the next section, we discuss the proposed conceptual framework in detail. Through this study, we propose a comprehensive definition of EE that takes into account its multifaceted nature.

\section{Conceptual Framework and Hypotheses}

"Customers do not buy goods or services: [T]hey buy offerings which render services which create value" [47].

One of the most important aspects for a firm to be in business is profitability. However, a service firm's profitability, to a great extent, is determined by its employees and its customer responses. In a service firm, employees and customers have a close and direct interaction [48], which affects the customers' responses. Therefore, it is essential for the service providers (employees) to deliver high-quality service levels. They represent the whole firm and also play an important role in shaping the customers' perceptions of service quality [38]. In the service industry, premium price behavior can be achieved primarily through the employees of the organization who act as an agent of the organization and help provide the customer with the right service.

\subsection{Employee Engagement}

Past research has shown that in order to deliver high levels of service quality, the employees have to be satisfied because satisfied employees are more involved in their jobs; if they are more committed and loyal towards the organization, they will provide a high quality of service [49]. Figure 1 depicts the process of employee engagement, which has been derived from the managerial interviews and the literature review.

\subsubsection{Employee Satisfaction}

Employee job satisfaction has been defined as "a pleasurable or positive emotional state resulting from the appraisal of one's job or job experiences" [50]. Job satisfaction is an emotional reaction to overall job circumstances and different job factors like the supervisor, pay, coworkers, etc. [51]. The internal quality of the work environment also contributes to employee satisfaction, which is measured by the feelings that employees have toward their job, colleagues, and company [52]. Various studies have noted that employee satisfaction affects customer satisfaction [53]. This can be attributed to the various employee roles, which keeps the employees aware of the organizational goals [54].

Employees who are satisfied with the organization can influence the firm's profitability through a better quality of service [55]. Satisfaction also affects turnover and absenteeism [56] and quality of work [49]. However, not all studies have a consensus that employee satisfaction improves a firm's performance. For instance, Brown and Peterson [51] concluded that employee satisfaction has a very low level of influence on a firm's performance. The value of employee satisfaction is also related to various job outcomes like job involvement, turnover, employee attendance, employee identification, etc. [57]. Employee Identification has been defined as "A psychological state wherein an individual perceives himself or herself to be part of a larger whole" and organizational identification as "a state wherein individuals perceive themselves to be part of a larger organization" [37]. From the above, it can be hypothesized that:

H1 Employee satisfaction has a positive influence on employee identification.

\subsubsection{Employee Identification}

Employee Identification towards the brand has been derived from the "social identity theory." Social identity has been defined as "that part of an individual's self-concept which derives from his knowledge of his membership of a group (or groups) together with the value and emotional significance attached to the membership" [58]. The theory is about the

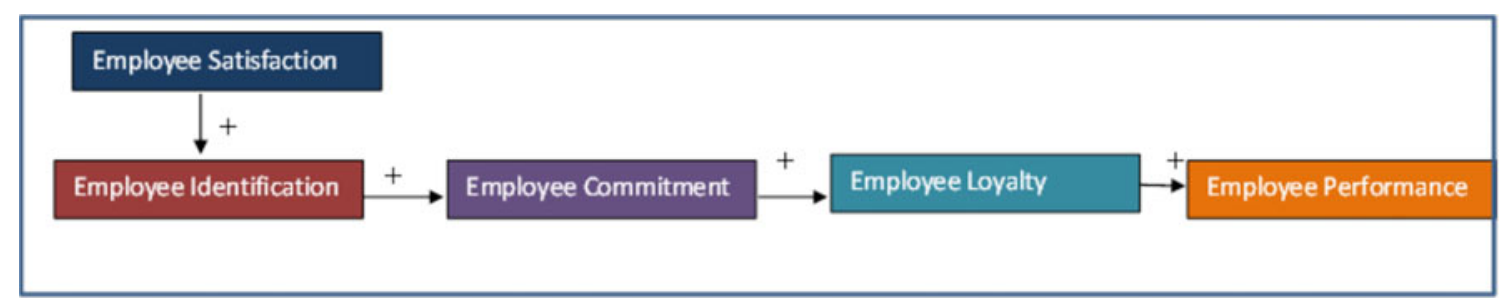

Fig. 1 Employee engagement- the construct 
individual's self-concept, which is derived from the perceived membership of a particular social group. Every organization is also a social group, wherein each member (employee) develops his/her self-concept on the basis of his/her association with the group (organization).

Employees who identify themselves with the organization are intertwined with the success and failure of the brand [59]. Identification can be enhanced through emphasis on brand distinctiveness, competition, charismatic leadership, individual mentorship [60], and a strong organizational culture with common rituals and symbols. Further, identification can also be enhanced among the employees if the brand values are communicated to them [61]. Employee identification has been considered as a precursor to employee commitment [45], which, in turn, is a precursor to employee loyalty [62]. In EE literature, engagement is considered the degree to which an individual is attentive and absorbed in the performance of their roles [28]. In other words, EE is considered to be synonymous with employee identification. Employee commitment is defined as: "the extent of psychological attachment of employees to the brand, which influences their willingness to exert extra effort towards reaching the brand" [59]. Most often, it has been defined as the emotional and intellectual commitment to the organization [63] or the amount of discretionary effort exhibited by employees in their jobs. Therefore, from the above, we can hypothesis that:

H2 Employee identification has a positive impact on employee commitment.

\subsubsection{Employee Commitment}

Organizational commitment or employee commitment towards the organization consists of affective commitment, continuance commitment, and normative commitment. Affective commitment is defined as: "The employee's emotional attachment to, identification with, and involvement in the organization." Continuance commitment is defined as: "An awareness of the costs associated with leaving the organization; employees whose primary link to the organization is based on continuance commitment remain because they need to do so." Normative commitment is defined as: "a feeling of obligation to continue employment." Organizational commitment induces functional extra-role behavior [64]. Therefore, it is essential for organizations to have highly committed employees. The commitment should be affective commitment, as that is the only psychological commitment the employee has towards the organization and this arises out of identification. In EE literature, several of the authors use terms such as commitment [30], an amalgam of commitment, loyalty, productivity, and ownership [31], to define EE. It has been studied that employees with the highest levels of commitment perform $20 \%$ better and are $87 \%$ less likely to leave the organization [65]. This indicates that employee commitment is an antecedent to loyalty where loyalty is considered in terms of the length of service, within the construct of continuance or calculative commitment. Loyalty has been defined as, "wholehearted devotion to an object" [66]. The object of loyalty can be a person, a group of persons, an organization (a church, a college or a firm), a cause, or a country. Loyalty develops over time and is an outcome of shared experiences. Employee loyalty is not restricted only to the given roles and responsibilities, but it also includes maintaining the trade secrets of the organization. From the above, we can theorize that:

H3 Employee commitment has a positive impact on employee loyalty.

\subsubsection{Employee Loyalty}

Schrag [67] noted that employee loyalty to an organization comprises of well wishing, identification, reciprocity, and sacrifices. He further notes that loyalty can motivate an employee to work for the organization more than his expected role and employees who are loyal to their organizations meet customers' needs and deliver high levels of customer service. Employees are also a source of differentiation, especially in industries where product and pricing strategies between competitors are similar. Employees who are loyal to the organization possess a positive attitude. This positive attitude of employees creates a positive attitude in consumers, which leads to higher satisfaction among customers [46].

Performances of employees in a service industry are evaluated on the basis of their behavior rather than measurable outcomes they can achieve [68]. The employees are evaluated on the basis of their effort, commitment, teamwork, customer orientation, and all other factors that contribute to improved service quality [54]. Internal branding should focus on the employees' attitudes toward a brand, as it would affect the employees' delivery of the brand promise [59]. Thus, it can be hypothesized:

H4 Employee loyalty leads to better employee performance.

\subsection{Antecedents of Employee Engagement}

\subsubsection{Employee Training and Orientation}

The service sector is dependent on the knowledge levels and skill sets of its employees. Therefore, company-based training 
is an important investment [69]. Further, the nature of the service industry is highly personal, and hence, it is essential for the organizations to align their employees' behavior to the organizational values and goals [70]. Access to training, career opportunities, work/life balance, and empowerment to make decisions are important for employees. Thus, for firms to foster a culture of engagement, they should design measures and evaluate proactive workplace policies and practices that help attract and retain talent with skills and competencies necessary for growth and sustainability. When employees receive resources from their organization, they feel obliged to repay the organization with greater levels of engagement as per the social exchange theory [25]. Moreover, firms with effective employee training and orientation activities can distinguish themselves from competitors [71], reduce the cost of employee acquisition, improve employee relations, and increase employee retention [72] through higher employee satisfaction [73].

Employees would be committed to the organization, only if they understand the organization's goals and their responsibilities towards these goals [74]. The alignment of organizational values and goals is possible through internal communication and training [9]. Training and orientation not only align the employees to organizational goals and values, but also improves the satisfaction level of employees [52]. From the above discussion, we can hypothesize that:

H5a Employee training and orientation has a positive impact on employee satisfaction.

\subsubsection{Employee Branding}

Product branding attributes can be applied to the branding activities of an employee [71]. Every firm would like to create loyalty and satisfaction and to develop an emotional attachment with its employees. In service firms, it is especially critical for the organization to align their employees' behavior to the organizational values and goals as employees are the face of the organization. This would also increase the commitment of the employees towards the organization, as they would understand the organizational goals and their responsibilities towards these goals [74]. Therefore, the branding activities of a firm ensure that employees transfer the brand values while delivering the brand promise and foster higher employee engagement and reputation [91]. Further, employees who are more satisfied also create better relationships with customers [52]. Therefore, we hypothesize that:

H5b Employee branding has a positive impact on employee satisfaction.
4.3 Consequences of Employee Engagement on the Firm's Performance

Employees are sustainable service differentiators who are expected to consistently deliver positive service attitude. It is this service attitude which makes employees a competitive advantage for firms [8]. Valuable, rare, inimitable, and nonsubstitutable resources are a competitive advantage of the firm that enhances the firms' performance [75], and employees inarguably happen to be one such resource. Evaluations in the service industry which are linked to service-related behaviors induce the employees to engage in a behavior that is conducive to improved service quality [76]. The attitudinal and behavioral responses are very important in the service industry where the customer contact is high because of the interactive nature of service delivery [77]. These behaviors can enhance or worsen the customers' perceptions of the service encounter and their judgments (brand image) of the organization [78]. The relationship between employee satisfaction and employee productivity or service quality has a huge impact on the customers of the firm [20]. The improved employee performance along with high customer engagement value [86] can positively impact firm profitability and also create value for the firm. Since we are not testing the relationship between EE and firm performance (beyond the scope of this study), we propose that:

P1 Employee performance has a positive impact on firm performance.

\section{Measures}

To achieve the objectives of the study, a conceptual model has been proposed (as depicted in Fig. 1) based on the literature review and managerial interviews. EE factors have been discussed without any consensus in the literature; therefore, we resorted to managerial interviews globally for better clarity and depth on the construct. Managerial interviews not only provided us deeper insights into the antecedents (branding activities and training and orientation) and the process of EE, but they also provided us with information on the current practices from the industry and their own experiences.

\subsection{Scale Development}

The initial scales used for the study were developed through an extensive review of the relevant literature, and interviews with the managers, in keeping with the specific context of the study. The scale to understand whether an organization carried out employer branding activities or not was adapted from Hah et al. [92]. The five-item orientation and training scale, which 
measure employees' perceptions towards orientation and training, was adapted from Punjaisri and Wilson [79]. The employee satisfaction scale was adapted from Macdonald and Macintyre [57]; it measures the employee's satisfaction towards the employer. The employee identification scale captures the sense of belonging of employees to the brand and their sense of pride and ownership towards the employer; this was adapted from Punjaisri et al. [59]. The scale for employee commitment was adapted from the research of Mohr et al. [80]; it reflects the employees' emotional attachment to the brand. The employee loyalty scale measures the intentions of the employees to stay with the brand; this was adapted from Boselie and DerWiele [81]. The employee performance scale, which was adapted from Anderson [82] scale, measures the extent to which employees deliver the brand promise and perform in the given environment. All the scales are measured on a five-point Likert scale, which ranges from "strongly agree" to "strongly disagree." This is because respondents readily understand how to use the scale [83], and in the past literature, this has been used extensively to measure attitudes [84].

\subsection{Pretest}

The first step in scale purification is to test the reliability of the scale by determining its Cronbach's alpha coefficients. This is in accordance with the recommendations made by Churchill [85]. Therefore, to test the reliabilities of the factors, we conducted a pilot study. The pilot study was conducted among service firms in two countries (India and the USA). The data was collected from over 120 employees of 15 firms in each country through both online and offline surveys. The online survey was administered through Google Docs.

The Cronbach's alpha coefficient for the orientation and training and branding activities scale was 0.7648 and was 0.9384 , respectively. The Cronbach's alpha for employee satisfaction was 0.844 , employee identification was 0.8524 , employee commitment was 0.2031 , employee loyalty was 0.8205 , and employee performance was 0.4356 . Since the Cronbach's alphas of employee commitment and employee performance were less than 0.5 , we refined these scales with the help of managerial interviews and literature support. In essence, we had to remove some scale items from each of the factors or reword some of the items to better suit the context of the study.

The next step in the scale development process is establishing the scale validity. We established the nomological validity of the scale with the help of experts in the field. We presented the scales to a panel of researchers at a large international conference and obtained feedback. Over a dozen managers and 20 academicians also reviewed the scales for its nomological validity. There was clarity on all the constructs except the construct of branding activities. Hence, we choose to refine those scale items.

\subsection{Scale Refinement}

Although the scale to measure the brand development activities of the organization towards its employees was adapted from the "employee branding" scale of Hah et al. [92] and had a Cronbach's alpha of 0.9384 , the scale was modified since the four items from the original scale were unclear in meaning to the employees. This could be because of the different settings in which the scale has been used. Hah et al. [92] considered students for their study, while we considered executives from the service industry for validating our scale. Further, the study conducted by Hah et al. [92] was restricted to one industry, whereas our study spans across the service sector. Before excluding items from the scale, we interviewed the managers from a few organizations to understand their perspective on those items. Managers noted that the original scale items ("provides a happy work environment," "values and makes use of my creative thinking," and "provides an exciting work environment") do not measure brand value; rather they measure the work environment within the organization, which may vary across departments. After excluding these items, which were not representative of the brand value; our Cronbach's alpha for brand development activities improved from 0.9384 to 0.9393 .

The scale for employee commitment was modified from the research of Churchill [85]; it reflects the employees' emotional attachment to the brand. In the pretest, the original scale provided a Cronbach's alpha of 0.2031 . This scale had two negatively worded items and three positively worded items which we tested separately. The Cronbach's alpha for the positively worded items was 0.7323 and the Cronbach's alpha for the negatively worded items was 0.4128 . Upon interviewing the respondents, we could conclude that the two negatively worded items ("I have minimal commitment to this organization" and "I do not feel emotionally attached to this organization") were found to lack clarity and appeared confusing. We therefore excluded them in order to refine the scale and have a better internal consistency and nomological validity. The Cronbach's alpha for the employee commitment scale improved drastically from 0.2031 to 0.7323 .

We tried using the employee performance scale from Anderson [82] to measure the extent to which employees deliver the brand promise and perform in the given environment. However, this scale provided a Cronbach's alpha that was as low as 0.4356 in our pretest study. Although we tried manipulating the items in various ways, we could not arrive at a good internal consistency of the items. Therefore, we analyzed the existing industry standards to develop the items for employee performance. We interviewed managers, who helped us identify the right items for inclusion, in order to measure 
employee performance. The managers we interviewed provided us with a new perspective to consider for developing these items, based on the prevalent performance measures of their organizations. Subsequently, we arrived at a two-item scale, which measures employees' performance and their scope for improvement and our Cronbach's alpha for this construct was 0.7894. Table 1 of Appendix 1 provides the final set of items of each measure along with the sources thereof.

\subsection{The EE Value}

The overall EE value can be categorized into four levels of engagement. They range from 20 to 100 (see Fig. 3 in Appendix 1). These score ranges are partitioned as quartiles (in intervals of 20) in a frequency distribution. A quartile score of 20-39 (disengaged) indicates lowest levels of all the EE factors and least engaged employees, implying that the firm needs to focus on enhancing every single factor of EE at an individual level. A quartile score of 40-59 (somewhat engaged) indicates that the employees are relatively less engaged with the firm, thereby implying that some of the factors of EE require immediate attention. A quartile score of 60-79 (moderately engaged) indicates a moderate level of EE, thereby implying that while the overall EE of the firm is sufficient for smooth functioning of the organization, there is scope of improvement in all aspects. A quartile score of 80-100 (super-engaged) is the highest one, which every firm should strive to achieve. This quartile score implies that the firm has followed all EE best practices and its employee performance is at its peak.

The results from the pilot study indicate that all the companies in the USA scored between 50 and 80, whereas the companies from the emerging markets were much lower (between 30 and 60) in their overall score of EE. Our results are supported by the Gallup study 2013, which indicates that there is a huge dearth of engaged employees in the world and the companies in the developed nation fair better than the companies in the emerging markets with respect to the level of EE. This helps establish "face validity" to our construct.

\subsection{Measuring EE on a Larger Scale}

The respondents in this study were middle-level and top-level executives of service firms. We identified respondents by requesting $\mathrm{HR}$ managers across organizations to circulate the questionnaire among their employees. A total of over 1,000 employees representing 30 firms (15 US companies, 15 Indian companies) were contacted as part of this exercise, and they were assured of the confidentiality of their responses and identities. We received responses from 685 employees representing all 30 firms (385 responses from the USA and 296 from India). However, only 232 (USA) and 213 (India) responses could be used for the study, as the remaining questionnaires were incomplete. Further, to avoid any common response bias, we rotated the order of the items on the survey that was administered to the respondents. The overall model fit was deemed to be acceptable because of the fit indexes $\left(x^{2}=1,046.478, d f=587, \mathrm{CFI}=0.94\right.$; Tucker-Lewis index $=0.92$, RMSEA $=0.02$ ). The path coefficient of the model was significant at $\alpha=0.05$ level.

\subsection{Data Analysis}

We examined all the scale items using the SmartPLS software package. We measured the Cronbach's alpha for all our factors, to ensure the internal consistency in the data. The Cronbach's alphas for our analysis were similar to the Cronbach's alphas of our pretest analysis, thus reassuring the reliability of the scales. We evaluated the proposed framework by running a confirmatory factor analysis (CFA) on the focal constructs of employee engagement (Fig. 2). We used the raw data as the input to this "partial least square"-based estimation procedure.

\subsection{Results}

Since our study spans across continents, we pooled the data collected from both the countries. In our combined data model, all the paths were significant at $5 \%$ level of significance. The standardized path coefficient for employee satisfaction to employee identification was 0.6747 ( $t$ stats -12.1230 and $p$ value $\leq 0.0$ ) indicating that if an employee is satisfied at his organization, then he would be positively inclined to connect with the organization and treat it as his own. From this, we find support for our first hypothesis, which states that employee satisfaction has a positive influence on employee identification. Evidence from the literature indicates that if an employee identifies with the organization, he/she will be committed towards the organization. The standardized path coefficient (0.5971) for this path also resonates the same with a $t$ stats of 8.4676 and $p$ value $\leq 0.0$ and this provides support to our $\mathrm{H} 2$, which states that employee identification has a positive impact on employee commitment. The standardized path coefficient for the path between employee commitments to employee loyalty is 0.5047 , with $t$ stats of 5.1187 and $p$ value $\leq$ 0.0 , indicating a positive relationship between employee commitment and employee loyalty, thereby providing support for our hypothesis 3, which states that employee commitment has a positive impact on employee loyalty. If an employee is loyal to the organization, then his intention to stay with the organization motivates him to perform better [67]. A standardized path coefficient of 0.3123 with $t$ stats of 2.94 and $p$ value $\leq 0.05$ provides support to the argument and our hypothesis 4 , which states that employee loyalty leads to better employee performance.

The partial least square analysis helped us understand the interdependencies between the various factors that influence 


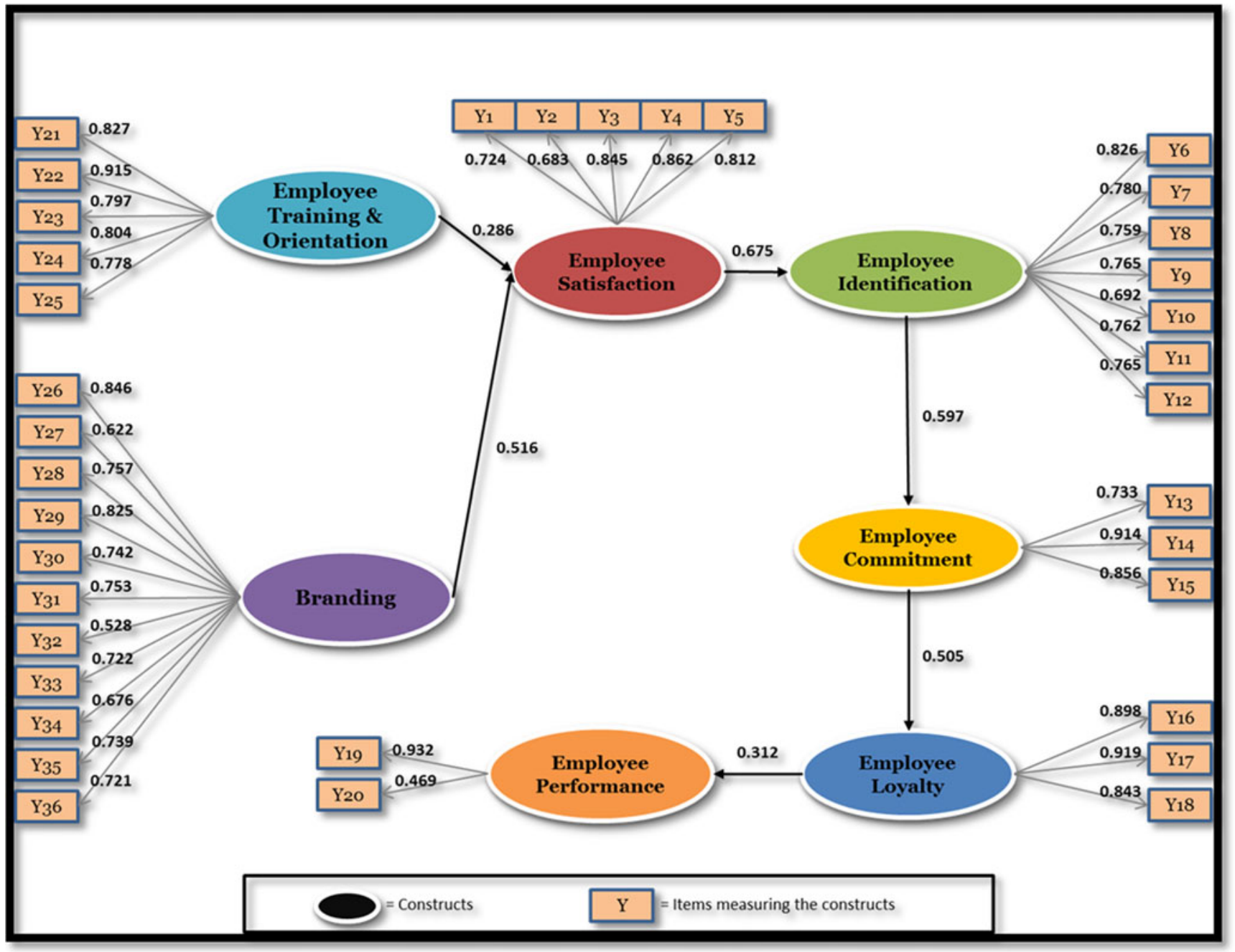

Fig. 2 Structural equation framework of employee engagement

EE. The insights gleaned from the qualitative interviews and the data collected from the companies surveyed provided us with guidelines to set the levels of $\mathrm{EE}$. The $\mathrm{EE}$ value for the combined data from the two countries ranged from 29 to 84 on a scale of 20 to 100 . All the companies in the emerging market scored between 29 and 60, indicating that although the employees of the firm were satisfied with the firm, they were not performing at their peak levels, as they were not completely committed and loyal to the firm. These metrics indicated that the firms needed to boost the commitment levels of the employees and implement loyalty-building initiatives. All the companies in the developed market scored between 48 and 82, which indicate a higher level of EE as expected.

\subsubsection{Impact of the Antecedents of Employee Engagement}

For employees to perform to the best of their capabilities, the organization has to play the role of a facilitator and enabler by providing the right input at the right time to its employees. In this framework, these inputs are the branding activities and the training and orientation activities of the firm. These inputs would enhance the relationship between employees and the organization. In the CFA analysis, the standardized path coefficients of training and orientation and branding to employee satisfaction were positive and significant at a value of 0.2858 ( $t$ stats 2.4252, $p$ value $\leq 0.05$ ) and 0.518007 ( $t$ stats 4.7309, $p$ value $\leq 0.05$ ), respectively. Thus, these provide support to our hypotheses $5 \mathrm{a}$ and $5 \mathrm{~b}$, which state that employee training and orientation has a positive impact on employee satisfaction and employee branding has a positive impact on employee satisfaction.

\section{Implications}

\subsection{Managerial Implications}

The employee engagement framework developed in this study throws light on the internal customers of the firm. It demonstrates the role played by employees in optimizing firm 
performance. All organizations (for profit as well as nonprofit) can use this framework to optimize their key resource: the employees; by implementing effective ways to maximize their engagement, in order to maximize the returns from the firm's key asset-the customers. Once the returns from the customers are maximized, value creation occurs for the firm. In other words, we define value creation as a well-defined strategy to maximize employee engagement in order to increase customer engagement value, thereby resulting in enhanced shareholder value. Therefore, marketing has to play a key role in communicating the value of engaging employees to all stakeholders in the organization and assist in ways to maximize the employee engagement. This section entails the managerial implications of our framework, along with a recommended roadmap to address those implications.

\subsection{Assessing EE Levels and Identifying Scope} for Improvement

Nurturing Employee Satisfaction As the proposed EE scale comprises of scores for all the EE factors, managers will be able to identify the focal areas of employee development that require their immediate attention. By analyzing and using this scale, firms can allocate their resources more effectively by focusing their resources effectively on the component where their employees are lacking. For instance, if the employees of the firm are not satisfied, then their interest levels towards dayto-day activities and operations of the organization will be very low, and because of this, there are high possibilities of absenteeism as well as diminished quality of work. All this will drain the organization of valuable time and money. Once managers trace the low EE score back to low levels of satisfaction, they could deploy various measures to enhance employee satisfaction. They can either assign work duties and responsibilities that correspond better with the skill sets of employees or provide continuous feedback to mentor their employees. They could also incentivize performance or provide flexible work hours.

Promoting Employee Identification Within the Organization If the employee is satisfied, but does not score equally high on employee identification, then he/she would not be able to imbibe and implement the organizational culture and values as well as the other employees do. This would hinder teambuilding activities and the growth of new ideas for employee development. In such a scenario, the organization could provide mentorships, idea development programs in addition to reinforcing the organizational culture and values.

Enhancing Employee Commitment Levels Even if the employee is satisfied and connects with the organization, he still may not be truly committed to the organization. If an employee is not truly committed to the firm, he/she will avoid taking any additional duties/responsibilities or will be on a constant lookout for alternative opportunities outside the firm. As a result, the firm will score low on employee commitment and will need to introduce initiatives focused on increasing this score. For instance, firms could review their work environment and performance incentives/rewards/benefits structure to ensure that those factors do a good job of assuring employees that both their presence and contributions are duly valued by the firm. In addition, the firm can undertake initiatives to convey the organizational goal, mission, and vision effectively to employees in a way that begin to feel a sense of commitment to the organization's cause and purpose.

Ensuring Employee Loyalty A loyal employee base is a valuable asset to any organization. Disloyal employees could let trade secrets out and may not treat customers fairly, among other implications. If an organization identifies employee loyalty as the roadblock in optimizing EE, then they should implement employee development programs that empower employees to update their knowledge and skills and present them with avenues for their individual growth. Organizations could also attempt to extend their relationship with the employee beyond the work sphere by sponsoring initiatives and extracurricular activities that foster inclusion and participation of employees' families.

Managing Employee Performance The most important aspect of the EE framework is employee performance. The entire framework of EE focuses on employee performance. Low employee morale and productivity will have a negative impact on not just employee behavior towards customers, but also the firm's bottom line. A firm with low-performing employees should investigate whether the gap in performance is caused due to a knowledge gap on the employees' part or due to a recruitment shortcoming that has caused the firm to hire inadequate candidates or place good candidates in jobs that they are not suited/qualified for. Accordingly, the firm can decide whether training and orientation programs, regular feedback/ mentorship programs, or performance incentives can enhance employee performance. If the firm identifies its recruitment policy to be the cause of low employee performance, it needs to revisit its candidate sourcing and interviewing strategy.

\subsubsection{Assessment of Organizational Orientation}

It is not sufficient for a firm to focus only on EE and assume an automatic maximization of profits. Firms will also have to focus on the key providers of its profits: the customers. Focusing and scoring high on $\mathrm{CE}$ are also essential and these have been discussed in the work of Kumar et al. [17] and Kumar [86].

Employees can enhance the firm's profitability even in a recessionary economic environment. In such an environment, firms face budgetary constraints that significantly affect their 
marketing plans, and, as a result, also their brand awareness and adoption levels. However, in such challenging times, firms can mitigate the risks posed by the dents in their marketing budgets if they have a highly engaged employee base which aggressively promotes the firm's brand and its products/services to its customers. This would ensure delivery of a superior customer experience, thereby increasing customer acquisition, retention, and referrals - all without any additional marketing investments.

Although EE has been discussed from the point of view of the final goal of profits, our framework is also relevant to nonprofit organizations as it would help them allocate their resources efficiently towards their employees and ensure that the employees stay enthused about and committed to the organization's cause. This would help in optimizing their funds towards their primary cause. This paper provides a concise definition for the concept of "employee engagement" and its process after analyzing all the contradictions in the literature and all the managerial interviews.

\section{Scope for Further Research}

1. The relationship between customer engagement and profitability has been established in the literature by Kumar et al. [17] and Kumar [86]. It would be interesting to study the impact of EE on this relationship and observe if EE can influence the relationship between customer engagement and firm profitability.

2. Since EE is an attitudinal measure with established scales, it would be interesting to measure customer engagement as an attitudinal measure as well, by developing scales for it. This would enable researchers to study the attitudinal behaviors of customers along with their resultant impact on profitability.
3. It would be interesting to analyze the dynamics due to the changes in the EE values. Time-varying parameter models can provide additional insights to the effect of employees' behaviors post-implementation of the recommended EE strategies.

4. Although the EE framework would be most beneficial to the service industry, it would be interesting to study the role of employees in the manufacturing industry to assess the relative importance of employees in different business settings.

5. The world is a global market and most brands are universal. This indicates that many organizations have their businesses spread across different continents and countries. It would be fascinating to analyze the EE framework of an organization with offices in multiple countries. This would help us understand whether the scores of EE differ across offices in different regions or if they remain the same. It would help in addressing higher level questions such as: "Does the culture of the country play a bigger role than the organizational culture in influencing EE?"

6. Survey-research in a cross-country scenario is a challenging task, as various factors such as culture, economic stability, etc. may require the researchers to develop different questionnaires [87], which could lead to different responses. However, it would be interesting to do a global study to analyze the differences across countries and measure their differential effects $[88,89]$ on employee engagement.

7. This being a very nascent topic in the field of marketing, there are multitudes of directions in which this topic can be explored. This can help pave the way for a new orientation, viz., engagement-oriented marketing, and a new lens to examine a firm's internal customers: the employees.

Acknowledgments We would like thank the editor, the reviewers, Gayatri Shukla, Dr. Alok Saboo, Dr. Denish Shah, and Dr. Nita Umashankar.

\section{Appendix 1}

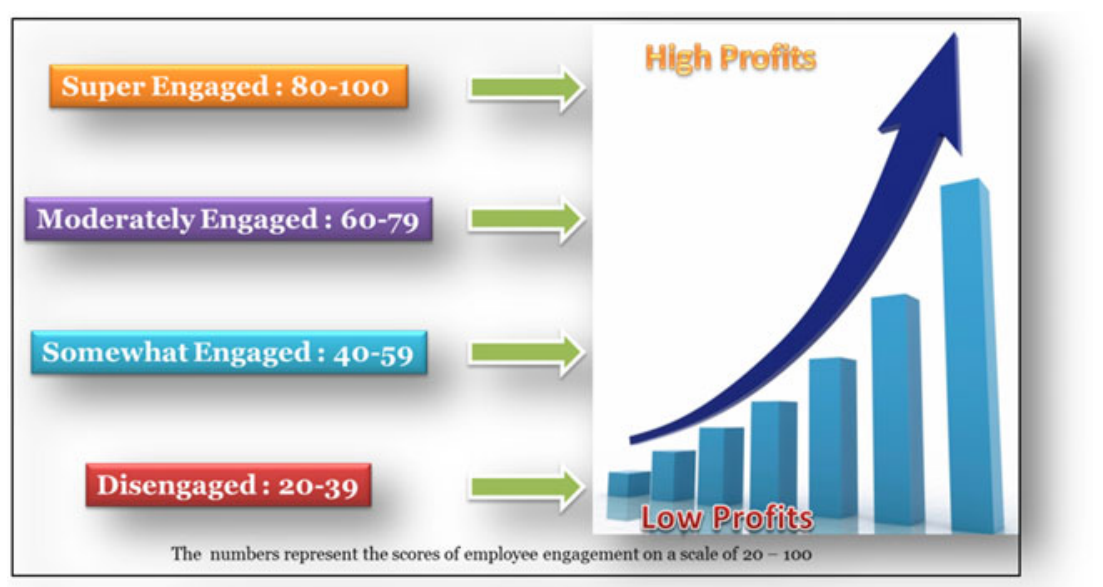

Fig. 3 Employee engagement and firm profitability 
Table 1 Components of employee engagement construct

\begin{tabular}{|c|c|c|c|}
\hline Construct & Adapted from & Items & $\begin{array}{l}\text { Cronbach's } \\
\text { alpha }\end{array}$ \\
\hline Branding & $\begin{array}{l}\text { Hah et al. [92] and } \\
\text { managerial interviews }\end{array}$ & $\begin{array}{l}\text { 1. Provides a career-enhancing experience } \\
\text { 2. Is a springboard for enhancing my talent } \\
\text { 3. Recognizes/appreciates individual work contributions } \\
\text { 4. Provides an attractive overall compensation package } \\
\text { 5. Provides job security within the organization } \\
\text { 6. Offers good promotion opportunities } \\
\text { 7. Provides hands-on, cross-functional experience } \\
\text { 8. Provides an opportunity to teach others what one has learnt } \\
\text { 9. Has supportive and encouraging supervisors and colleagues } \\
\text { 10. Produces innovative products/services } \\
\text { 11. Has novel work practices }\end{array}$ & 0.9393 \\
\hline Orientation and training & Punjaisri and Wilson [79] & $\begin{array}{l}\text { 1. Provides an orientation program which inspires me to appropriately } \\
\text { deliver the brand promise } \\
\text { 2. Provides me with appropriate skills to deliver the brand promise } \\
\text { based on the brand standards } \\
\text { 3. Keeps the employees informed about things that are relevant to them } \\
\text { 4. Clearly communicates the brand mission and clarifies my role in } \\
\text { relation to the brand mission } \\
\text { 5. Provides all essential information for me to provide services } \\
\text { according to the brand expectations }\end{array}$ & 0.7648 \\
\hline Employee satisfaction & $\begin{array}{l}\text { Macdonald and } \\
\text { Macintyre [57] }\end{array}$ & $\begin{array}{l}\text { 1. I receive recognition for a job well done } \\
\text { 2. I feel close to the people at work } \\
\text { 3. I feel good about working at this company } \\
\text { 4. I feel secure about my job } \\
\text { 5. I believe management is concerned about me }\end{array}$ & 0.844 \\
\hline Employee identification & Punjasiri et al. [59] & $\begin{array}{l}\text { 1. I am proud to tell others that I am part of the organization } \\
\text { 2. I feel a sense of ownership towards this organization } \\
\text { 3. My sense of pride towards the organizational brand is reinforced } \\
\text { by its brand-related messages } \\
\text { 4. I view the success of the brand as my own success } \\
\text { 5. The organization is like a family to me } \\
\text { 6. When I talk about this organization, I usually say "we" rather than "they" } \\
\text { 7. When someone praises this brand, it feels like a personal compliment }\end{array}$ & 0.8524 \\
\hline Employee commitment & $\begin{array}{l}\text { Mohr et al. [80] and managerial } \\
\text { and employee interviews }\end{array}$ & $\begin{array}{l}\text { 1. My commitment to deliver the brand increases along with my } \\
\text { knowledge of the brand } \\
\text { 2. I am very committed to delivering the brand promise to our customers } \\
\text { 3. This organization has a great deal of personal meaning for me }\end{array}$ & 0.7323 \\
\hline Employee loyalty & Boselie and DerWiele [81] & $\begin{array}{l}\text { 1. I will be happy to spend the rest of my career in this organization } \\
\text { 2. I do not have an intention to change to another organization at this moment } \\
\text { 3. My intention to stay is driven by the fact that I am competent in } \\
\text { delivering the brand promise }\end{array}$ & 0.8205 \\
\hline Employee performance & Managerial interviews & $\begin{array}{l}\text { 1. My performance in the last appraisal exceeded expectations } \\
\text { 2. The amount of opportunity for my performance improvement at } \\
\text { my organization is high }\end{array}$ & 0.7894 \\
\hline
\end{tabular}

\section{References}

1. Ramani G, Kumar V (2008) Interaction orientation and firm performance. J Mark 72(1):27-45
2. Robert L, Vargo S, Brien M (2007) Competing through service: insights from service-dominant logic. J Retail 83(1):5-18

3. Miller L (2012) ASTD 2012 State of the industry report: organizations continue to invest in workplace Learning. ASTD. http://www. astd.org. Accessed 15 May 2012] 
4. Greenberg H (2009) Effectively training notes users - a comparison of the end user training options for IBM lotus notes. www.tlc.com. Accessed 12 Apr 2012

5. Rayport J, Jaworski B (2005) Best face forward: why companies must improve their service interfaces with customers. Harvard Business School Press, Boston

6. Kelly T (2011) FedEx delivery man caught throwing computer monitor over gate; video goes viral (WATCH). The Huffington Post. http://www.huffingtonpost.com/2011/12/21/fedex-deliveryman n 1162743.html. Accessed 30 Oct 2013

7. The National Bureau of Economic Research (2013) http://www.nber. org/digest/aug03/w9524.html. Accessed 12 Dec 2013

8. Harris F, Chernatony L (2001) Corporate branding and corporate brand performance. Eur J Mark 35(3/4):441-451

9. Thomson K, Chernatony L, Arganbright L, Khan S (1999) The buyin benchmark: how staff understanding and commitment impact brand and business performance. J Mark Manag 15(8):819-835

10. CBS News (2009) Something special about Southwest Airlines. www.cbsnews.com. Accessed 30 June 2013

11. Reinartz W, Thomas J, Kumar V (2005) Balancing acquisition and retention resources to maximize customer profitability. J Mark 69(1): 63-79

12. Eugene AW, Fornell C, Lehmann DR (1994) Customer satisfaction, market share and profitability: findings from Sweden. J Mark 58(3): 53-66

13. Reinartz W, Kumar V (2000) On the profitability of long-life customers in a noncontractual setting: an empirical investigation and implications for marketing. J Mark 64(4):17-35

14. Bernhart J (2013) Bernhart associates hiring survey. http://www. bernhart.com. Accessed Feb 2013

15. Kahn J (2013) Samsung's ad budget exploded past Apple and the rest of the field in 2012. http://9to5mac.com. Accessed May 2013

16. Fowler J (2012) 7 Companies with big advertising budgets. http:// www.investopedia.com. Accessed January 2013

17. Kumar V, Aksoy L, Donkers B, Venkatesan R, Wiesel T, Tillmanns S (2010) Undervalued or overvalued customers: capturing total customer engagement value. J Serv Res 13(3):297-310

18. Edvardsson B, Johnson M, Gustafsson A, Strandvik T (2000) The effects of satisfaction and loyalty on profits and growth: products versus services. Total Qual Manag Bus Excell 11(7):917-927

19. Zeithaml V, Bitner M (2002) Services marketing: integrating customer focus across the firm, 2nd edn. McGraw-Hill, New York

20. Anderson EW, Fornell C, Rust RT (1997) Customer satisfaction, productivity and profitability: differences between goods and services. Mark Sci 16(2):129-145

21. Kumar V, Shah D, Venkatesan R (2006) Managing retailer profitability — one customer at a time. J Retail 82(4):277-294

22. Richman A (2006) Everyone wants an engaged workforce how can you create it? Workspan 49:36-39

23. Coffman C, Gonzalez-Molina G (2002) Follow this path: how the world's greatest organizations drive growth by unleashing human potential. Warner, New York

24. Weber L (2013) Excited about your lob, if so you are a global minority. www.blogs.wsj.com. Accessed 15 Oct 2013

25. Kahn W (1990) Psychological conditions of personal engagement and disengagement at work. Acad Manag J 33:692-724

26. Maslach C, Schaufeli WB, Leiter MP (2001) Job burnout. Annu Rev Psychol 52(1):397-422

27. Harter JK, Schmidt FL, Hayes TL (2002) Business-unit-level relationship between employee satisfaction, employee engagement, and business outcomes: a meta-analysis. J Appl Psychol 87(2):268

28. Saks A (2006) Antecedents and consequences of employee engagement. J Manag Psychol 21(7):600-619

29. Macey W, Schneider W, Barbera K, Young S (2009) Employee engagement: tools for analysis, practice, and competitive advantage. Wiley-Blackwell, Chichester
30. Fleming JH, Coffman C, Harter JK (2005) Manage your human sigma. Harv Bus Rev 83(7):106-115

31. Wellins R, Concelman J (2004) Creating a culture for engagement. Workforce performance solutions 4, 1-4. www.WPSmag.com. Accessed 15 June 2013

32. Robinson D, Perryman S, Hayday S (2004) The drivers of employee engagement. Institute for Employment Studies, Brighton

33. Schaufeli W, Salanova M, González-Romá V, Bakker A (2002) The measurement of engagement and burnout: a two sample confirmatory factor analytic approach. J Happiness Stud 3(1):71-92

34. Masson R, Royal M, Agnew T, Fine S (2008) Leveraging employee engagement: the practical implications. Ind Organ Psychol 1(1):5659

35. Little B, Little P (2006) Employee engagement: conceptual issues. J Org Cult Commun Confl 10(1):111-120

36. Vargo S, Lusch R (2008) Service-dominant logic: continuing the evolution. J Acad Mark Sci 36:1-10

37. Rousseau MD (1998) Why workers still identify with organizations. J Organ Behav 19(3):217-233

38. Parasuraman A, Zeithaml V, Berry L (1985) A conceptual model of service quality and its implications for future research. J Mark 49(4): $41-50$

39. Bitner M (1990) Evaluating service encounters: the effects of physical surroundings and employee responses. J Mark 54(2):69-82

40. Bettencourt AL, Brown S (2003) Role stressors and customeroriented boundary-spanning behaviors in service organizations. J Acad Mark Sci 31(4):394-408

41. Kelley WS (1992) Developing customer orientation among service employees. J Acad Mark Sci 20(1):27-36

42. Bienstock CC, DeMoranville C, Smith R (2003) Organizational citizenship behaviour and service quality. J Serv Mark 17(4):357378

43. Lee J, Miller D (1999) People matter: commitment to employees, strategy and performance in Korean firms. Strateg Manag J 20(6): 579-593

44. Mittal V, Kamakura W (2001) Satisfaction, repurchase intent, and repurchase behavior: investigating the moderating effect of customer characteristics. J Mark Res 38(1):131-142

45. Burmann C, Zeplin S (2005) Building brand commitment: a behavioral approach to internal brand building. J Brand Manag 12(4):279300

46. Allen N, Grisaffe D (2001) Employee commitment to the organization and customer reactions: mapping the linkages. Hum Resour Manag Rev 11(3):209-236

47. Gummesson E (1995) Relationship marketing: it's role in the service economy. In: Glynn W, Barnes J (eds) Understanding services management. Wiley, New York, pp 244-268

48. Chase BR (1981) The customer contact approach to services: theoretical bases and practical extensions. Oper Res 21(4):698-705

49. Silvestro R, Cross S (2000) Applying the service-profit chain in a retail environment: challenging the satisfaction mirror. Int J Serv Ind Manag 11(3):244-268

50. Locke E (1976) The nature and causes of job satisfaction. In: Donnettee MD (ed) Handbook of industrial and organizational psychology. Rand McNally, Chicago

51. Brown S, Peterson R (1993) Antecedents and consequences of salesperson job satisfaction: meta-analysis and assessment of causal effects. J Mark Res 30(1):63-77

52. Heskett L, James T, Jones O, Loveman G, Sasser W, Schlesinger L (1994) Putting the service profit chain to work. Harv Bus Rev 2:105-111

53. Koys D (2001) The effects of employee satisfaction, organizational citizenship behavior and turnover on organizational effectiveness: a unit-level, longitudinal study. Pers Psychol 54(1):101-114

54. Schneider B, Bowen D (1985) Employee and customer perceptions of service in banks: replication and extension. J Appl Psychol 70(3): $423-443$ 
55. Yee WYR, Yeung ACL, Cheng TCE (2008) The impact of employee satisfaction on quality and profitability in high-contact service industries. J Oper Manag 26(5):651-668

56. Fisher CD, Locke EA (1992) The new look in job satisfaction research and theory. In: Cranny C.J., Cain Smith P, Stone EF (eds) Job satisfaction: how people feel about their jobs. The Free Press, New York

57. Macdonald S, Macintyre P (1997) The generic job satisfaction scale: scale development and its correlates. Employee Assistance Q 13(2):1-16

58. Tajfel H (1978) Social categorization, social identity, and social comparisons. Differentiation between social groups. Academic, London

59. Punjaisri K, Evanschitzky H, Wilson A (2009) Internal branding: an enabler of employees' brand-supporting behaviours. Serv Manag 20(2):20-26

60. Mael F, Ashforth B (1992) Alumni and their alma mater: a partial test of the reformulated model of organizational identification. J Organ Behav 13(2):103-123

61. Bergstrom A, Blumenthal D, Crothers S (2002) Why internal branding matters: the case of Saab. Corp Reput Rev 5(2-3):2-3

62. Pritchard RD (1992) Organizational productivity. In: Dunnette MD, Hough LM (eds) Handbook of industrial and organizational psychology, vol 3, 2nd edn., pp 443-471

63. Shaw JD, Gupta N, Delery J (2005) Voluntary turnover and organizational performance. Acad Manag J 48(1):50-68

64. Meyer J, Allen N (1991) A three-component conceptualization of organizational commitment. Hum Resour Manag Rev 1:61-89

65. Lockwood N (2007) Leveraging employee engagement for competitive advantage. Soc Hum Resour Manag Res Q 1:1-12

66. Ladd J (1967) Loyalty. In: Edwards P (ed) The encyclopedia of philosophy. Macmillan, London, pp 97-98

67. Schrag B (2009) The moral significance of employee loyalty. Bus Ethics Q 11(1):41-66

68. Anderson E, Oliver R (1987) Perspectives on behavior-based versus outcome-based sales force control systems. J Mark 51(4):76-88

69. Bo H (2006) Company-based determinants of training and the impact of training on company performance: results from an international HRM survey. Pers Rev 36(2):311-331

70. LePla J, Parker L (1999) Integrated branding: becoming brand-driven through company-wide action. Quorum, London

71. Davies G (2007) Employer branding and its influence on managers. Eur J Mark 42(5):667-681

72. Ritson M (2002) Marketing and HR collaborate to harness employer brand power, marketing, p. 24

73. Winterton J (2004) A conceptual model of labor turnover and retention. Hum Resour Dev Int 7(3):371-390

74. Zyman S, Brott A (2002) The end of advertising as we know it
75. Barney J (1991) Firm resources and sustained competitive advantage. J Manag 17(1):175-190

76. George W (1990) Internal marketing and organizational behavior: a partnership in developing customer-conscious employees at every level. J Bus Res 20(1):63-70

77. Gronroos C (1983) Strategic management and marketing in the service sector. Marketing Science Institute Working Paper Series, Report No. 83-104. Cambridge, MA: Marketing Science Institute 31-43

78. Bitner M, Booms B, Tetreault M (1990) The service encounter: diagnosing favorable and unfavorable. J Mark 54(1):71-84

79. Punjaisri K, Wilson A (2007) The role of internal branding in the delivery of employee brand promise. J Brand Manag 15(1):57-70

80. Mohr J, Fisher R, Nevin J (1996) Collaborative communication in inter firm relationships: moderating effects of integration and control. J Mark 60(3):103-115

81. Boselie P, DerWiele T (2002) Employee perceptions of HRM and TQM and the effects on satisfaction and intention to leave. Manag Serv Qual 12(3):165-172

82. Williams J, Anderson S (2002) Job satisfaction and organizational commitment as predictors of organizational citizenship and in-role behavior. J Manag 17(3):601-617

83. Malhotra K, Birks D (2000) Marketing research: an applied approach. Prentice-Hall, Harlow, European ed., financial times

84. Kinnear T, Taylor J (1996) Marketing research: an applied approach. McGraw-Hill, New York

85. Churchill G Jr (1979) A paradigm for developing better measures of marketing constructs. J Mark Res 16:64-73

86. Kumar V (2013) Profitable customer engagement: concepts, metrics $\&$ strategies. Sage, New Delhi

87. Kumar V (2000) International marketing research. Prentice Hall, Upper Saddle River

88. Baumgartner H, Steenkamp JBE (2001) Response styles in marketing research: a cross-national investigation. J Mark Res 38:143-156

89. De Jong MG, Steenkamp JBE, Fox JP (2007) Relaxing measurement invariance in cross-national consumer research using a hierarchical IRT model. J Consum Res 34(2):260-278

90. Rafiq M, Pervaiz KA (2000) Advances in the internal marketing concept: definition, synthesis and extension. J Serv Mark14(6): 449-462

91. Dortok A (2006) A managerial look at the interaction between internal communication and corporate reputation. Corp Reput Rev 8(4):322-338

92. Hah LL, Ewing M, Berthon P (2005) Captivating company: dimensions of attractiveness in employer branding. International Journal of Advertising 24 (2) 151-172 